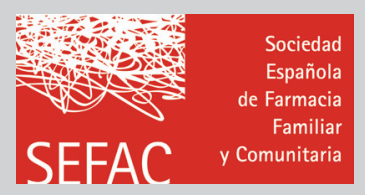

\title{
Deshumanización de la atención sociosanitaria
}

\author{
Lola Murillo \\ Farmacéutica comunitaria en Sevilla. Vicepresidenta $3^{\text {a }}$ de SEFAC.
}

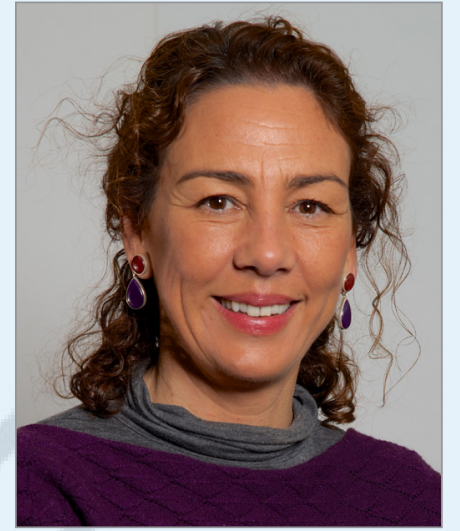

Lola Murillo
En España el 18\% de la población tiene más de 65 años y de estos más del 6\% tiene más de 80. En el 2050 seremos el tercer país más envejecido del mundo. Además, el 87\% de los mayores desea vivir en sus casas el mayor tiempo posible, pero cuando esto no es posible, o ellos o sus familiares toman la decisión de que lo hagan en un centro sociosanitario. La decisión no es sencilla, pero sin duda es necesaria.

Estos datos tan contundentes hacen necesaria una reflexión, ya que muchos de nosotros que hoy leemos esto cómodamente desde la salud y la juventud relativa, deberíamos pensar cómo querríamos que fuese el lugar en el que pasemos nuestra vejez y los cuidados que nos gustaría recibir, tanto personales como sanitarios.

Una residencia sociosanitaria no es un hospital ni un hotel. Son establecimientos en los que viven personas que por su estado de salud no pueden vivir solas y necesitan cuidados sanitarios profesionales. Son, o deberían ser, lo más parecido a seguir viviendo con la autonomía que su salud les permita pero con la confianza de que aunque ésta desgraciadamente irá mermando, allí tendrán cubiertas sus necesidades sociales (de compañia, atención, higiene, alimentación) y sanitarias.

Llevamos años hablando de la cronicidad (no los suficientes como para estar preparados para ella), se ha definido una y mil veces, en todos los congresos sanitarios, cursos, libros, artículos... Y cómo no, en leyes y estrategias ministeriales no se habla de otra cosa, pero ¿realmente entendemos lo que implica? Es complicado contestar a esta pregunta, pero podemos entender que difícilmente podremos afrontarla desde la fragmentación actual que vive el sector sanitario porque es imposible de entender y manejar si cada uno lo hace desde su pequeña parcela porque no se ve de forma global, porque para poder manejarla debemos dejar atrás muchos prejuicios personales, profesionales y sanitarios y verla de una forma holística sin egoísmos.

La cronicidad es el gran problema al que se enfrentan las sociedades que no han sabido ver hasta hora nada más que lo agudo, lo inmediato, lo urgente. Podríamos estar hablando de muchas cosas, pero si hablamos de salud o de no salud, el problema se refiere a pacientes con patologías crónicas, los más débiles y frágiles, condición a la que frecuentemente se suma la edad avanzada con el considerable agravamiento que supone

Según el perfil de personas mayores de España (CSIC 2015) hay 8.442.427 personas mayores de 65 años, de ellas el 6\% (506.645) tiene más de 80 años. Sin embargo, actualmente sólo hay 5.340 centros sociosanitarios con capacidad para 359.035 personas.

Estos datos sorprenden, más cuando a fecha de abril de 2015, sólo en Andalucía había 118.655 mayores dependientes a la espera de recibir ayudas o ingresar en una residencia de titularidad pública. Triste, muy triste, porque hay cientos de plazas libres, sobre todo en los centros sociosanitarios privados y concertados, y a las que muchos de estos pacientes tendrían acceso si al menos tuviesen esas ayudas que no reciben en muchas ocasiones hasta que es demasiado tarde.

Hablamos de nosotros, nuestros padres, tíos o abuelos o de nuestra vecina del quinto, Carmen, a la que conocemos desde siempre y a la que vemos como cada día está más desvalida y sola; a la que antes ayudábamos a subir las bolsas de la compra, pero que ahora nos preocupa que no sale de su casa; que vemos que necesita que la cuiden; que nos preocupa cada mañana si estará bien, pero que nuestras propias preocupaciones $\mathrm{y}$ nuestra falta de tiempo nos hace que no la llamemos y que en días no sepamos cómo se encuentra. 
De Carmen va la cronicidad y los cambios sociales, económicos y sanitarios que son necesarios. Ha vivido sola con sus achaques mientras ha podido. Ahora viene a su casa una asistente social unas horas para echarle una mano, pero eso ya no es suficiente. Carmen precisa ser atendida a todas horas y eso sólo es posible en una residencia.

El problema es que para los que toman las decisiones, nuestra amiga es sólo un número, triste muy triste, porque además con ella y con muchos como ella, los que toman las decisiones hacen números y, claro, los números no salen. Y no salen porque cada vez hay más Carmen que viven más años y necesitan más recursos y esos recursos no están o se los han llevado otros. Pero Carmen no es sólo nuestra vecina, madre o abuela, somos nosotros en unas pocas décadas.

Los que toman decisiones lo hacen pensando en los números de hoy porque a menudo lo urgente aplaza lo importante, pero es insostenible no planificar, prever y proveer el futuro. La cronicidad de hoy se multiplicará mañana y pasado y en el 2050 tendremos una sociedad tan envejecida que si no planteamos nuevas posibilidades y estrategias la realidad de nuestro futuro puede ser tan o, incluso, más cruel de lo que es hoy con Carmen.

Y demasiado a menudo y ante la apisonadora de la austeridad que no planifica ni siquiera a medio plazo los que deciden, como deciden, han decidido que en esas residencias sociosanitarias también hay que hacer números, porque hay muchas que producen mucho gasto $\mathrm{y}$, como todo lo que tocan, los que deciden tocan aquello que funciona: la atención que Carmen recibe desde su farmacia comunitaria de toda la vida, que lleva años yendo a la residencia, con el farmacéutico comunitario al que conocen de años porque va a llevar la medicación y habla con Carmen. Y todo porque quieren tratarla como si estuviese en un hospital y que su atención siga siendo un número, el de su cama, sin conocerla y deshumanizando la relación.

\section{Propuesta de SEFAC}

Además, la tendencia de las centrales de compras, la preparación de los SPD (sistemas de reacondicionamiento) a gran escala, la selección de medicamentos a través de subastas, la reducción del vademécum al que tienen acceso los pacientes, etc. están condicionando la prestación farmacéutica que reciben los mayores que residen en centros sociosanitarios. Por este motivo, y con el objetivo de mejorar esa prestación farmacéutica y mantener el vínculo de los pacientes con sus farmacéuticos comunitarios, SEFAC ha planteado una propuesta encaminada a mejorar también la calidad del servicio que desde las farmacias comunitarias se puede ofrecer a los centros sociosanitarios.

La propuesta de SEFAC sobre el papel de los farmacéuticos comunitarios en la atención farmacéutica a los centros sociosanitarios (próximamente podrá consultarse integra en www.sefac.org) pasa por satisfacer las necesidades farmacoterapéuticas particulares de los pacientes residentes en los establecimientos de este ámbito asistencial (desde la adquisición de medicamentos y productos sanitarios hasta el seguimiento de los tratamientos farmacológicos).

Para ello se plantea sustituir los tradicionales depósitos de medicamentos por servicios de farmacia comunitaria vinculados a una farmacia, con servicios profesionales asistenciales y realizados por farmacéuticos comunitarios capacitados para ello. Estos servicios serían concertados a través de los Colegios Oficiales de Farmacéuticos, quienes también pactarían las condiciones para la facturación y el cobro de esos servicios, y se trabajaría de forma coordinada con el resto de profesionales que intervienen en la atención a las personas mayores, participando si fuera necesario, en sesiones de formación conjunta.

El establecimiento de esos servicios de farmacia comunitaria debería basarse fundamentalmente en dos criterios: la calidad del servicio (catálogo de servicios asistenciales que ofrece la farmacia, capacitación del personal, experiencia) y la accesibilidad (proximidad, horario, etc.).

Desde SEFAC pensamos que esta propuesta no solo permitiría mantener el vínculo de los pacientes que residen en centros sociosanitarios con sus farmacéuticos de confianza, sino también mejorar la calidad del servicio y garantizar que la prestación farmacéutica en este ámbito asistencial se basa en criterios asistenciales y profesionales. Porque nuestra Carmen, y el resto de pacientes, se merecen que los cuidados que reciban estén a la altura de sus necesidades. 